\title{
A COMPARATIVE STUDY ON THE FORECAST OF FRESH FOOD SALES USING LOGISTIC REGRESSION, MOVING AVERAGE AND BPNN METHODS
}

\author{
Wan-I Lee \\ Department of Marketing and Distribution Management, National Kaohsiung First University of Science and \\ Technology, Kaohsiung, Taiwan \\ Cheng-Wu Chen \\ Earth Observation and Data Analysis Center, National Cheng Kung University, Tainan 701, Taiwan, R.O.C, \\ chengwu@mail.nkmu.edu.tw \\ Kung-Hsing Chen \\ HI-LIFE International Co., Ltd., 3F, 502, Rueiguang Rd., Neihu District, Taipei City, Taiwan \\ Tsung-Hao Chen \\ Department of Business Management, Shu-Te University, Kaohsiung, Taiwan. \\ Chia-Chi Liu \\ College of Management, National Kaohsiung First University of Science and Technology
}

nstitue of Maritime Information and Technology, National Kaohsiung Marine University, Kaohsiung, Taiwan. Global

Follow this and additional works at: https://jmstt.ntou.edu.tw/journal

Part of the Management Information Systems Commons

\footnotetext{
Recommended Citation

Lee, Wan-l; Chen, Cheng-Wu; Chen, Kung-Hsing; Chen, Tsung-Hao; and Liu, Chia-Chi (2012) "A COMPARATIVE STUDY ON THE FORECAST OF FRESH FOOD SALES USING LOGISTIC REGRESSION, MOVING AVERAGE AND BPNN METHODS," Journal of Marine Science and Technology. Vol. 20: Iss. 2, Article 4.

DOI: $10.51400 / 2709-6998.1832$

Available at: https://jmstt.ntou.edu.tw/journal/vol20/iss2/4

This Research Article is brought to you for free and open access by Journal of Marine Science and Technology. It has been accepted for inclusion in Journal of Marine Science and Technology by an authorized editor of Journal of Marine Science and Technology.
} 


\section{A COMPARATIVE STUDY ON THE FORECAST OF FRESH FOOD SALES USING LOGISTIC REGRESSION, MOVING AVERAGE AND BPNN METHODS}

\section{Acknowledgements}

The authors would like to thank the National Science Council of the Republic of China, Taiwan, for their financial support of this research under Contract Nos. NSC 100-2221- E-022-013-MY2, NSC100-2628-E-022-002-MY2, NSC 98- 2221-E-366-006-MY2 and 97-2221-E-327-024. The authors are also most grateful for the POS data from the Hi-Life company and kind assistance of Prof. Chee-Fai Yung, Editor-in-chief of JMST, and the constructive suggestions from anonymous reviewers all of which has led to the making of several corrections and suggestions that have greatly aided us in the presentation of this paper. 


\title{
A COMPARATIVE STUDY ON THE FORECAST OF FRESH FOOD SALES USING LOGISTIC REGRESSION, MOVING AVERAGE AND BPNN METHODS
}

\author{
Wan-I Lee ${ }^{1}$, Cheng-Wu Chen ${ }^{2,3}$, Kung-Hsing Chen ${ }^{4}$, Tsung-Hao Chen ${ }^{5}$, and \\ Chia-Chi Liu ${ }^{6}$
}

Key words: Moving average, BPNN, logistic regression, fresh food in POS database.

\section{ABSTRACT}

Different prediction methods give different performance predictions when used for daily fresh food sales forecasting. Logistic Regression (LR) is a good choice for binary data, the Moving Average (MA) method is good for simple prediction, while the Back-Propagation Neural Network (BPNN) method is good for long term data. In this study we develop and compare the performance of three sales forecasting models, based on the above three prediction methods, for the forecasting of fresh food sales in a point of sales (POS) database for convenience stores. Fresh food is characterized by two factors: its short shelf-life and its importance as a revenue producer for convenience stores. An efficient forecasting model would be helpful to increase sales volume and reduce waste at such stores. The correctness of the prediction rate is a good way to compare the efficacy of different models which is the method used here. The research results reveal that LR performs better than the other methods although MA is better suited to the management of convenience stores.

Paper sumitted 05/19/09; revised 03/02/10, 08/23/10; accepted 09/14/10. Author for correspondence: Cheng-Wu Chen (e-mail: chengwu@mail.nkmu.edu.tw). ${ }^{1}$ Department of Marketing and Distribution Management, National Kaohsiung First University of Science and Technology, Kaohsiung, Taiwan.

${ }^{2}$ Institue of Maritime Information and Technology, National Kaohsiung Marine University, Kaohsiung, Taiwan.

${ }^{3}$ Global Earth Observation and Data Analysis Center, National Cheng Kung University, Tainan 701, Taiwan, R.O.C.

${ }^{4}$ HI-LIFE International Co., Ltd., 3F, 502, Rueiguang Rd., Neihu District, Taipei City, Taiwan.

${ }^{5}$ Department of Business Management, Shu-Te University, Kaohsiung, Taiwan.

${ }^{6}$ College of Management, National Kaohsiung First University of Science and Technology.

\section{INTRODUCTION}

With the changing of the structure of society and households, the way fresh food is sold in the market is rapidly changing. Freshness and rapid speed of turnover are important consideration. Sellers must maintain high standards for facilities and equipment, be serious about the quality of production and have suitable options for sources raw materials. The period that one can keep fresh food, from the day of production to when it must be discarded, is shorter than for cooked food, which means that it is important to predict how much fresh food will be required in the market. In this study we will focus on making this type of prediction with different forecasting sales models.

Reliable prediction of sales is of immense benefit to a business because it can improve the quality of the business strategy and decrease costs due to waste, thereby increasing profit. To improve an enterprise's competitiveness, the manager must make correct decisions using the available information. This "forecasting" is viewed as an important part of decision making. Forecasting of future demand is central to the planning and operation of the retail industry. Managers need sales forecasts as essential input to many decision activities in a variety of areas such as marketing, sales and production.

Before regression analysis, the training data have to satisfy four assumptions: normality and resemblance or variation, independence of raw data, linearity and zero error average. The increasing usage of statistics and probability has made forecasting techniques become more critical. As technology requirements increase, so does the demand for greater exactness and efficiency. A growing number of studies are being made which shed some light on these two independent requirements for computing with complex statistics or algorithms. These forecasting systems must deal with the following constraints:

- Substitution of most of the items collected is subjective.

- Long lead time needs to be taken into consideration when 
producing and planning sources for a mid-term horizon

- Influence of explanatory variables. These factors can include: weather data, holidays, marketing actions, promotions, fashion, even economic environment.

These types of constraints are being incorporated by more and more researchers who are applying sales forecasting models to deal with forecasting problems. All of these models possess fault tolerance ability and high-speed computability. In the past, the three most commonly applied methods have been Logistic Regression (LR), the Moving Average (MA) method, and Back-Propagation Neural Networks (BPNNs) [86, $87,89,111,132,135,149,160,161,180]$. These methods have been applied in many different areas including for ecological and microbial studies, in Morgan Stanley Capital International (MSCI), for finding ecosystem attributes, and so on. Some have concluded that the BPNN methods perform better than others, however these approaches are inherently different and whether one approach has better diagnostic performance than the other is not easy to determine.

The purpose of this current study is to build sales forecasting model utilizing the Logistic Regression, Moving Average and Back-Propagation Neural Network methods for the prediction of daily fresh food sales. The goal is to deal with short-term sales forecasting for convenience stores. The uncertainty and the complex relationship between the data will be considered in proposed sales forecasting models.

\section{SALES FORECASTING}

The importance of sales forecasting for a firm [127] is best expressed by what happens when it is absent [159]. An efficient forecasting system can help a firm improve machine utilization, reduce inventory, achieve greater flexibility to change and increase profits [85]. Sales forecasting is particularly important because its outcome affects many functions in the organization [130]. Business operations can only respond retroactively, leading to lost orders, inadequate service and poorly utilized production resources in the short term; financial and market decisions leading to misallocation of resources so that the organization's continuing existence may be brought into question in the longer term [88].

Collectively, there is some empirical evidence indicating that the subjective techniques popular for all types of forecasting situations are effective. Among the statistical forecasting approaches, exponential smoothing has recently been gaining in popularity [84]. In particular, in recent years, extensions and modifications of the BPNN have been developed. The BPNN is the most common of the neural network applications having the advantage of yielding high classification accuracy [109]. However, this method has two problems, slow training speed and the likelihood of entering into a local minimum during the process. Moreover, in logistic regression, the model complexity is relatively, especially when no or few interaction terms and variable transformations are used [86].
The use of specific forecasting techniques is a crucial aspect of the forecasting process [128].

\section{RESEARCH METHOD}

\section{Research Subject and Data Collection}

Taiwan's Hi-Life convenience store chain is selected as the research subject. We collected data on 35 days of fresh food sales from the POS database of the Hi-Life convenience stores. The sales data included number of sales and amount of fresh food discarded. Fresh foods herein are comprised of four kinds of sandwich, three kinds of hand-made rolls, two kinds of rice balls and sushi. The data are shown in Appendix 1 .

In this study, a "single product" is defined as the test unit. Information includes the type of fresh food, ordering cycle, quantity ordered, arrival date and expiration date. The ordering cycle is defined as daily. Quantity ordered is defined ranging from zero to ninety-nine. Arrival date is defined as arrival on the next morning following ordering. Finally, expiration date is defined as one and a half days after arrival at the store.

\section{Logistic Regression (LR)}

Logistic distribution is a model transform method that utilizes logic analysis after the selection of variables. The following Cumulative Probability Function is utilized for the logistic regression analysis [133]:

$$
P_{i}=F\left(Z_{i}\right)=F\left(\beta_{0}+\beta_{1} X_{1}\right)=\frac{1}{1+e^{-Z_{i}}}=\frac{1}{1+e^{-\left(\beta_{0}+\beta_{1} X_{i}\right)}}
$$

Eq. (1) can be rewritten as Eq. (2) and comprises the logistic regression analysis model used in this study

$$
Z_{i}=\beta_{0}+\sum_{j=1}^{n} \beta_{j} X_{i j}+e_{i} \quad(i=1,2, \ldots, n)
$$

From a pool of $\mathrm{n}$ samples, $\mathrm{n}-1$ can be fitted to an LR model defined by $\left(p_{m}\right)=\alpha+\sum_{i=1}^{10} \beta_{i} X_{i}$, where $p_{m}$ is the probability of discarded items; $\alpha$ and $\beta_{i}$ are unknown parameters that determine the shape of the logistic curve described. The unknown parameters $\alpha$ and $\beta_{i}$ are estimated using a maximumlikelihood approach. Meanwhile, the estimated parameters $\hat{\alpha}$ and $\hat{\beta}$ are used to calculate the probability of discarded items.

\section{Back-Propagation Neural Network}

The most common learning mechanism is the "back propagation" approach [134]. The Back-Propagation Neural Network (BPNN) is a supervised learning network well suited for prediction $[49,52]$. In BPNN one attempts to minimize the mean-square output error throughout the entire training set. It is similar to the statistical calculation of the best fitting line for 


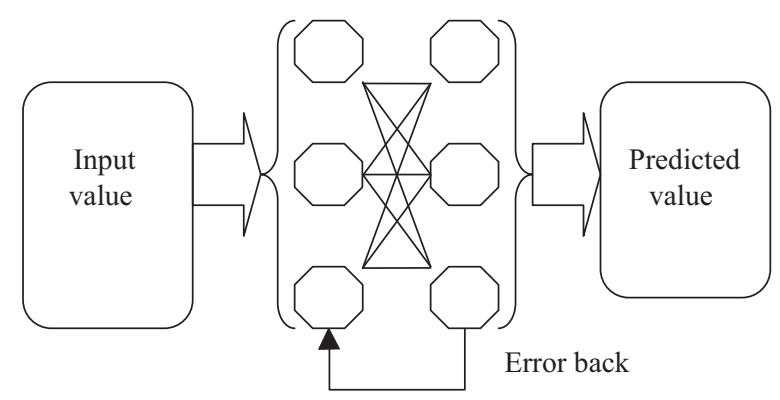

Fig. 1. Mapping of BPNN.

dispersed points. The output of the network, after introduction of the input data, is compared to the true output. The process is shown in Fig. 1.

The training data may be sometimes is over-fitted by the training network [83] which compromises the performance with new data. By halting the training from time to time and testing the performance with a new data set, one can avoid the over-fitting condition. This difficulty is less of a problem for large data sets. Once the network has been trained it must still be tested again with further cases with known outcomes. The Work Toolbox of MATLAB is used to develop and simulate the BPNN. One and two hidden layers are selected as the input for the model. The learning rate is 0.01 and the error less than $10^{-11}$. Here, we choose the sample (e.g., sandwich A and sushi) for input, and run the training function. Finally, a predicted value is generated and a correct percentage is calculated.

\section{Moving Average (MA)}

MA is simply a time series analysis forecasting method. The advantage of MA is that it is simple and easy to use. It also gives a basic and efficient tendency index. Based on this, this method is commonly used to make forecasts from historical data. Eq. (3) can be used to find the simple moving average by first computing the sum of the observations and then dividing by the number of observations. The structure is shown in Fig. 2. In other words, we calculute the average of a circle, where the average value is an expected value $X_{n+1}$.

$$
M A=X_{n+1}=\sum_{i=1}^{n}\left[\frac{X_{i}}{n}\right]
$$

where

$n$ : days of moving average $\sum_{i=1}^{n} x_{i}:$ the sum value of recall $n$ days include calculate day.

\section{Error Calculation}

The correct percentage means the percentage of correct predictions while the incorrect percentage means the failure to predict all values. The correct forecast percentage is the summation of the predicted values, divided by the total sample
Table 1. LR model prediction results.

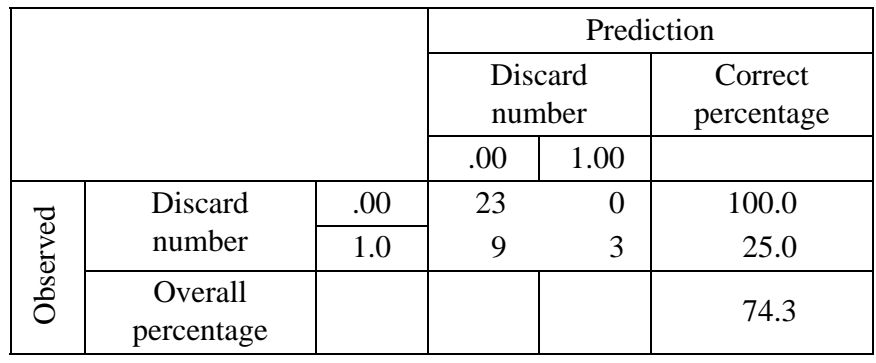

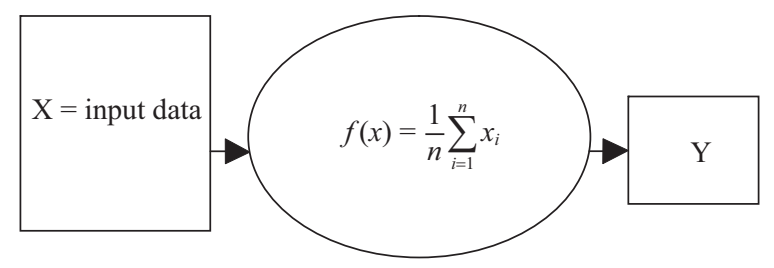

Fig. 2. Mapping of the MA method.

number. For example, in Table 1, it can be seen that the correctly predicted value for sandwich A is 26 and the incorrect prediction is 9. The correct percentage for sandwich $\mathrm{A}$ is $74.3 \%$. Here, we define error in the correct percentage as the incorrect percentage.

\section{EXPERIMENTS}

Forecasting the correct percentage is a simple and fast method for evaluating the performance of a prediction model. In the study, three models are developed and evaluated. SPSS 13.0 is used to analysis the LR model, MATLAB 7.0 is used for the BPNN model and EXCEL 2003 is utilized to evaluate the MA model.

\section{Logistic Regression}

The LR prediction model is developed to predict the number of items sold and the number that have to be discarded. The number of items sold is the independent variable and the discard number is the dependent variable. If the value of the dependent variable is 0 it means that no items are discarded; 1 means that some items are discarded. The LR model is verified by SPSS 13.0. The prediction results for sandwich A are shown in Table 1 and overall results are shown in Table 3.

\section{Back-Propagation Neural Network}

The parameters for the BPNN prediction model used are shown in Table 2.

In addition, the expected values are predicted using different periods of data (including 7 days, 14 days, 21 days, and 28 days). The correct percentage prediction for sandwich $\mathrm{A}$ is $71.43 \%$ for 28 days, $61.9 \%$ for 14 days, $50 \%$ for 21 days and $32.14 \%$ for 7 days. The prediction results are shown in Table 3 and the architecture for the method is shown in Fig. 3. 
Table 2. Parameters for BPNN.

\begin{tabular}{|l|l|}
\hline Parameter & 1 \\
\hline Input & 1 \\
\hline Layers & 2 \\
\hline First adaption function & tansig \\
\hline Second adaption function & purelin \\
\hline Training function & taming \\
\hline Epoch limit & 3000 \\
\hline Error & $10-11$ \\
\hline Neuron network choice & Network increase \\
\hline Initial weight & 1 \\
\hline Bias weights & 1 \\
\hline Perform function & MSE \\
\hline
\end{tabular}

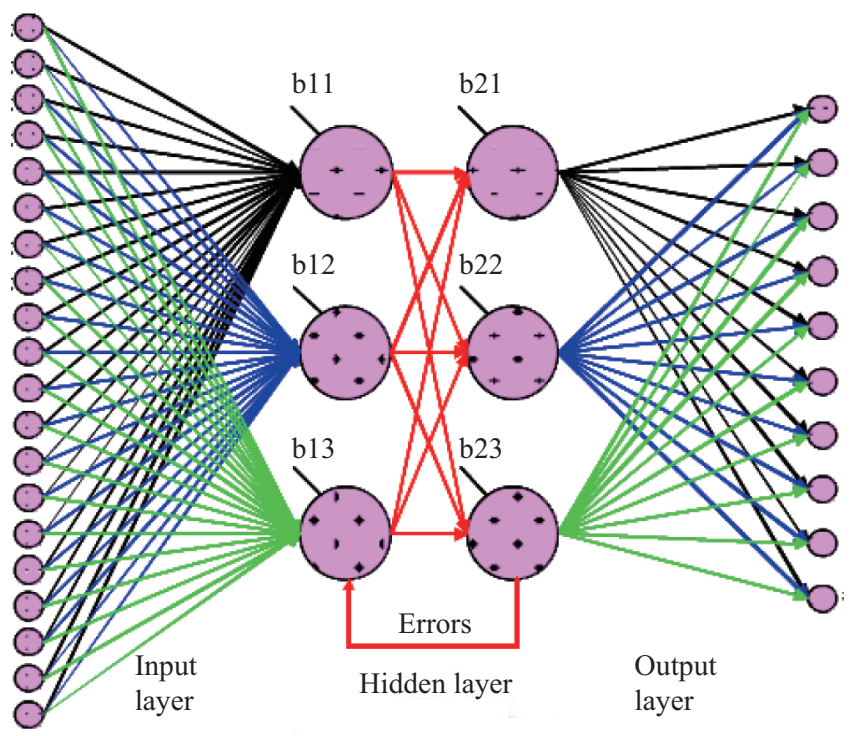

Fig. 3. BPNN network.

\section{Moving Average}

The differences in data are checked by T-testing, and then induced [87]. After induction, we find that there are two variables distinguished by date. One is holiday and the other is ordinary day. After distinction, data are input into the MA model and used to predict expected values. The prediction results are shown in Table 3. The correct percentage prediction of MA is $78.57 \%$ (for hand-made rolls C).

\section{DISCUSSION}

Recently, soft computing and artificial intelligence have been successfully applied to the systemengineering [1-82, 90-108, 110, 113-127, 131, 136-158, 162-179, 181]. The BPNN, MA and LR prediction models are used to predict the number of sales of fresh food at a convenience store. Results are shown in Table 3. It can be seen that the MA method gives the highest correct percentage for sandwich $\mathrm{A}$; the BPNN method gives the highest correct percentage for sushi; the LR model gives the highest value for all others. On the whole, it is clear that the performance of LR is better than that of MA or BPNN. The standard error obtained with LR is less than with other methods, which means less variance in the LR model. The error value of LR is less than that of either MA or BPNN, as shown in Table 4. In Table 3, it can be seen that, for most samples, the LR forecast is higher than that of the other methods. The correct BPNN percentage for sushi is higher than that obtained by the other methods while the correct percentage predicted by MA is greater for sandwich $\mathrm{A}$ and hand roll $\mathrm{C}$ than that for the others. The standard error for LR is 0.108964 which is less than that of the other methods.

In this study, the correct percentage obtained by LR is higher than that obtained with the other methods. However, this result is different from that found in past related studies, where it was found that the BPNN performed better than the other methods. Why does this difference occur? We explore some inferred reasons. One reason is that the BPNN program is very subjective, so different models may produce different results. Table 2 shows parameters used in this study for the BPNN model. The second reason is the differences in the samples. For example, as noted by Song, researchers use different methods on different samples, but even the same method will perform differently with different samples. In other words, one method is not always suitable for all samples. Different samples have different features and are suitable for data with different periods. In Table 3 it can be seen that performance is better for long period data. According to these results, BPNN is more suitable for samples with long periods. Thus, we find that LR gives better correct percentage performance than others; its standard error is also better than the other methods. This means that LR will not be influenced by different types of samples. On the whole, the explanatory ability of LR is better than that of the other methods. In addition, there are software tools available to calculate LR. On the other hand, MA is a fast and easy method, which can be used on any sample. It is easy to understand the overall tendency, although its performance is not as good. The error rate of BPNN is too high. The error rate of MA is also higher than that of LR which is $20.3 \%$. Although still high, a $20 \%$ error rate is acceptable for small samples. In conclusion, MA and BPNN are not suitable for predicting the amount of fresh food sales.

In order to reduce costs, we would suggest that Hi-Life managers utilize MA to make sales predictions. The MA model is effective at showing first time tendencies and is also an easy method to use. Although the prediction precision of LR is greater than that of MA, it needs complex statistical software to use. In addition, LR requires the data to be switched into binary data. Only if managers are familiar with statistical software, could they use the LR model. The BPNN 
Table 3. Correct percentages for LR, MA and BPNN.

\begin{tabular}{|c|c|c|c|c|c|c|}
\hline & LR (Enter) & MA & BPNN (7 days) & BPNN (14 days) & BPNN (21 days) & BPNN (28 days) \\
\hline sandwich A & $74.30 \%$ & $75 \%$ & $32.14 \%$ & $61.90 \%$ & $50 \%$ & $71.43 \%$ \\
\hline sandwich B & $77.10 \%$ & $39.29 \%$ & $42.86 \%$ & $42.86 \%$ & $50 \%$ & $14.29 \%$ \\
\hline sandwich C & $77.10 \%$ & $57.14 \%$ & $39.29 \%$ & $28.57 \%$ & $21.43 \%$ & $42.86 \%$ \\
\hline hand roll A & $82.90 \%$ & $42.86 \%$ & $10.71 \%$ & $14.29 \%$ & $14.29 \%$ & $14.29 \%$ \\
\hline hand roll B & $77.10 \%$ & $53.57 \%$ & $10.71 \%$ & $28.57 \%$ & $28.57 \%$ & $42.86 \%$ \\
\hline hand roll C & $60 \%$ & $78.57 \%$ & $46.43 \%$ & $57.14 \%$ & $57.14 \%$ & $28.58 \%$ \\
\hline rice ball A & $85.70 \%$ & $39.29 \%$ & $35.71 \%$ & $33.33 \%$ & $35.71 \%$ & $57.15 \%$ \\
\hline rice ball B & $94.30 \%$ & $35.71 \%$ & $0.00 \%$ & $28.57 \%$ & $35.71 \%$ & $0.00 \%$ \\
\hline sushi & $71.40 \%$ & $71.43 \%$ & $0.00 \%$ & $52.38 \%$ & $57.14 \%$ & $100 \%$ \\
\hline Average & $79.70 \%$ & $52 \%$ & $21.79 \%$ & $34.76 \%$ & $35 \%$ & $37.14 \%$ \\
\hline S.E. & 0.108964 & 0.18384 & 0.1923006 & 0.193154805 & 0.191797384 & 0.324367728 \\
\hline
\end{tabular}

Table 4. Error for all samples by each method.

\begin{tabular}{|c|c|c|c|c|c|c|}
\hline & LR (Enter) & MA & BPNN (7 days) & BPNN (14 days) & BPNN (21 days) & BPNN (28 days) \\
\hline sandwich A & $25.70 \%$ & $25.00 \%$ & $67.86 \%$ & $38.10 \%$ & $50.00 \%$ & $28.57 \%$ \\
\hline sandwich B & $22.90 \%$ & $60.71 \%$ & $57.14 \%$ & $57.14 \%$ & $50.00 \%$ & $85.71 \%$ \\
\hline sandwich C & $22.90 \%$ & $42.86 \%$ & $60.71 \%$ & $71.43 \%$ & $78.57 \%$ & $57.14 \%$ \\
\hline hand roll A & $17.10 \%$ & $57.14 \%$ & $89.29 \%$ & $85.71 \%$ & $85.71 \%$ & $85.71 \%$ \\
\hline hand roll B & $22.90 \%$ & $46.43 \%$ & $89.29 \%$ & $71.43 \%$ & $71.43 \%$ & $57.14 \%$ \\
\hline hand roll C & $40.00 \%$ & $21.43 \%$ & $53.57 \%$ & $42.86 \%$ & $42.86 \%$ & $71.42 \%$ \\
\hline rice ball A & $14.30 \%$ & $60.71 \%$ & $64.29 \%$ & $66.67 \%$ & $64.29 \%$ & $42.85 \%$ \\
\hline rice ball B & $5.70 \%$ & $64.29 \%$ & $100.00 \%$ & $71.43 \%$ & $64.29 \%$ & $100.00 \%$ \\
\hline sushi & $28.60 \%$ & $28.57 \%$ & $100.00 \%$ & $47.62 \%$ & $42.86 \%$ & $0.00 \%$ \\
\hline Average & $20.30 \%$ & $48.00 \%$ & $78.21 \%$ & $65.24 \%$ & $65.00 \%$ & $62.86 \%$ \\
\hline S.E. & $25.70 \%$ & $25.00 \%$ & $67.86 \%$ & $38.10 \%$ & $50.00 \%$ & $28.57 \%$ \\
\hline
\end{tabular}

model is not suggested for short period prediction of fresh food sales.

\section{CONCLUSIONS}

This study proposes using Logistic Regression, Moving Average and Back-Propagation Neural Network methods for sales models designed to predict daily fresh food sales. We found that the correct percentage obtained by LR to be better than that obtained by the BPNN and MA models. This knowledge is valuable for fostering informed decision making by the company and for the application of forecasting models by academics in the fresh food setting. Future research could be done to extend the sales forecasting model to a variety of other products and to integrate the factor of climate to find rigorous sales trends. Furthermore, further research could be done to consider the distribution timing of logistics to forecast the sales of fresh food.

\section{ACKNOWLEDGMENTS}

The authors would like to thank the National Science Council of the Republic of China, Taiwan, for their financial support of this research under Contract Nos. NSC 100-2221E-022-013-MY2, NSC100-2628-E-022-002-MY2, NSC 982221-E-366-006-MY2 and 97-2221-E-327-024. The authors are also most grateful for the POS data from the Hi-Life company and kind assistance of Prof. Chee-Fai Yung, Editor-in-chief of JMST, and the constructive suggestions from anonymous reviewers all of which has led to the making of several corrections and suggestions that have greatly aided us in the presentation of this paper. 


\section{APPENDIX 1.}

35 days of data from the POS database for a Hi-Life convenience store in Taipei.

\begin{tabular}{|c|c|c|c|c|c|c|c|c|c|c|c|c|c|c|c|c|c|c|c|c|c|c|}
\hline \multirow[b]{2}{*}{ Date } & \multicolumn{2}{|c|}{$\begin{array}{c}\text { Sandwich } \\
\text { A }\end{array}$} & \multicolumn{2}{|c|}{$\begin{array}{c}\text { Sandwich } \\
\text { B } \\
\end{array}$} & \multicolumn{2}{|c|}{$\begin{array}{c}\text { Sandwich } \\
\text { C }\end{array}$} & \multicolumn{2}{|c|}{$\begin{array}{c}\text { Sandwich } \\
\text { D } \\
\end{array}$} & \multicolumn{2}{|c|}{$\begin{array}{c}\text { Hand roll } \\
\text { A }\end{array}$} & \multicolumn{2}{|c|}{$\begin{array}{c}\text { Hand roll } \\
\text { B }\end{array}$} & \multicolumn{2}{|c|}{$\begin{array}{c}\text { Hand roll } \\
\mathrm{C}\end{array}$} & \multicolumn{2}{|c|}{$\begin{array}{c}\text { Rich boll } \\
\text { A }\end{array}$} & \multicolumn{2}{|c|}{$\begin{array}{c}\text { Rich boll } \\
\text { B }\end{array}$} & \multicolumn{2}{|c|}{ Sushi } & \multicolumn{2}{|c|}{ Total } \\
\hline & sales & discard & sales & discard & sales & discard & sales & discard & sales & discard & sales & discard & sales & discard & sales & discard & sales & discard & sales & discard & sales & discard \\
\hline $10 / 17$ & 2 & 1 & 2 & 1 & 5 & 1 & 1 & 1 & 5 & 0 & 3 & 1 & 0 & 0 & 5 & 1 & 10 & 1 & 1 & 4 & 34 & 11 \\
\hline $10 / 18$ & 2 & 1 & 3 & 0 & 6 & 0 & 0 & 1 & 4 & 1 & 2 & 2 & 0 & 0 & 6 & 0 & 12 & 0 & 2 & 3 & 37 & 8 \\
\hline $10 / 19$ & 3 & 0 & 3 & 0 & 5 & 1 & 1 & 1 & 6 & 0 & 3 & 0 & 0 & 0 & 6 & 1 & 8 & 2 & 4 & 1 & 39 & 6 \\
\hline $10 / 20$ & 2 & 1 & 2 & 1 & 4 & 2 & 0 & 1 & 4 & 0 & 4 & 0 & 1 & 1 & 5 & 1 & 6 & 4 & 1 & 5 & 29 & 16 \\
\hline $10 / 21$ & 3 & 0 & 3 & 0 & 4 & 2 & 1 & 0 & 3 & 1 & 3 & 1 & 2 & 0 & 5 & 1 & 10 & 2 & 2 & 3 & 36 & 10 \\
\hline $10 / 22$ & 0 & 2 & 0 & 2 & 2 & 1 & 0 & 2 & 2 & 1 & 1 & 1 & 1 & 0 & 2 & 1 & 3 & 1 & 0 & 3 & 11 & 14 \\
\hline $10 / 23$ & 1 & 1 & 1 & 1 & 3 & 0 & 0 & 1 & 2 & 1 & 0 & 2 & 0 & 1 & 4 & 0 & 3 & 1 & 1 & 2 & 15 & 10 \\
\hline $10 / 24$ & 3 & 0 & 3 & 0 & 4 & 2 & 1 & 1 & 5 & 0 & 2 & 2 & 1 & 1 & 6 & 0 & 10 & 2 & 2 & 2 & 37 & 10 \\
\hline $10 / 25$ & 3 & 0 & 3 & 0 & 5 & 1 & 1 & 0 & 5 & 0 & 3 & 1 & 1 & 1 & 6 & 0 & 9 & 3 & 3 & 0 & 39 & 6 \\
\hline $10 / 26$ & 3 & 0 & 3 & 0 & 4 & 2 & 1 & 1 & 4 & 2 & 3 & 1 & 1 & 0 & 7 & 0 & 9 & 4 & 3 & 1 & 38 & 11 \\
\hline $10 / 27$ & 4 & 0 & 2 & 1 & 3 & 3 & 1 & 1 & 5 & 0 & 2 & 3 & 2 & 0 & 4 & 2 & 8 & 4 & 3 & 0 & 34 & 14 \\
\hline $10 / 28$ & 3 & 1 & 3 & 0 & 3 & 2 & 0 & 2 & 3 & 2 & 4 & 0 & 1 & 0 & 5 & 1 & 12 & 0 & 3 & 0 & 37 & 8 \\
\hline $10 / 29$ & 1 & 1 & 1 & 1 & 2 & 1 & 0 & 1 & 3 & 1 & 1 & 0 & 1 & 0 & 3 & 1 & 3 & 2 & 1 & 0 & 16 & 8 \\
\hline $10 / 30$ & 2 & 0 & 0 & 2 & 1 & 2 & 1 & 0 & 2 & 2 & 0 & 1 & 1 & 0 & 3 & 1 & 2 & 3 & 0 & 2 & 12 & 13 \\
\hline $10 / 31$ & 4 & 0 & 4 & 0 & 4 & 1 & 1 & 0 & 4 & 1 & 3 & 0 & 3 & 0 & 6 & 0 & 9 & 2 & 3 & 1 & 41 & 5 \\
\hline $11 / 1$ & 4 & 0 & 4 & 0 & 4 & 2 & 0 & 2 & 3 & 2 & 2 & 2 & 2 & 1 & 5 & 1 & 10 & 1 & 3 & 0 & 37 & 11 \\
\hline $11 / 2$ & 5 & 0 & 3 & 1 & 3 & 2 & 2 & 0 & 1 & 3 & 4 & 0 & 2 & 0 & 7 & 0 & 8 & 3 & 4 & 0 & 39 & 9 \\
\hline $11 / 3$ & 4 & 1 & 3 & 1 & 2 & 3 & 0 & 2 & 4 & 0 & 2 & 3 & 2 & 1 & 5 & 1 & 9 & 4 & 1 & 0 & 32 & 16 \\
\hline $11 / 4$ & 4 & 1 & 3 & 0 & 4 & 1 & 1 & 1 & 4 & 3 & 3 & 1 & 3 & 0 & 6 & 0 & 7 & 5 & 3 & 0 & 38 & 12 \\
\hline $11 / 5$ & 2 & 0 & 1 & 1 & 1 & 2 & 1 & 0 & 2 & 2 & 1 & 0 & 1 & 2 & 2 & 1 & 3 & 1 & 1 & 0 & 15 & 9 \\
\hline $11 / 6$ & 2 & 0 & 1 & 1 & 2 & 1 & 0 & 1 & 3 & 0 & 0 & 1 & 2 & 0 & 3 & 0 & 1 & 4 & 0 & 0 & 14 & 8 \\
\hline $11 / 7$ & 5 & 0 & 3 & 1 & 4 & 2 & 0 & 1 & 3 & 1 & 2 & 2 & 0 & 3 & 6 & 0 & 9 & 2 & 3 & 0 & 35 & 12 \\
\hline $11 / 8$ & 5 & 0 & 3 & 1 & 3 & 1 & 1 & 1 & 4 & 0 & 3 & 0 & 1 & 2 & 6 & 0 & 9 & 1 & 3 & 0 & 38 & 6 \\
\hline $11 / 9$ & 4 & 0 & 4 & 0 & 3 & 2 & 1 & 1 & 3 & 1 & 3 & 0 & 2 & 1 & 6 & 0 & 10 & 0 & 2 & 0 & 38 & 5 \\
\hline $11 / 10$ & 5 & 1 & 2 & 2 & 3 & 1 & 0 & 2 & 4 & 1 & 2 & 1 & 2 & 0 & 6 & 0 & 8 & 3 & 3 & 0 & 35 & 11 \\
\hline $11 / 11$ & 5 & 0 & 3 & 1 & 2 & 3 & 1 & 1 & 3 & 1 & 3 & 1 & 2 & 0 & 5 & 1 & 10 & 1 & 3 & 0 & 37 & 9 \\
\hline $11 / 12$ & 2 & 0 & 2 & 0 & 2 & 1 & 0 & 1 & 1 & 2 & 0 & 1 & 2 & 0 & 3 & 1 & 4 & 0 & 1 & 0 & 17 & 6 \\
\hline $11 / 13$ & 3 & 0 & 0 & 2 & 1 & 2 & 0 & 1 & 3 & 0 & 1 & 0 & 0 & 2 & 3 & 0 & 2 & 2 & 0 & 0 & 13 & 9 \\
\hline $11 / 14$ & 5 & 0 & 3 & 1 & 2 & 2 & 1 & 0 & 3 & 1 & 0 & 3 & 1 & 1 & 5 & 1 & 10 & 1 & 3 & 0 & 33 & 10 \\
\hline $11 / 15$ & 5 & 0 & 2 & 2 & 2 & 3 & 1 & 1 & 3 & 1 & 0 & 3 & 1 & 2 & 6 & 0 & 10 & 1 & 3 & 0 & 33 & 13 \\
\hline $11 / 16$ & 5 & 1 & 4 & 0 & 2 & 3 & 0 & 1 & 4 & 1 & 3 & 0 & 2 & 2 & 5 & 1 & 9 & 2 & 2 & 0 & 36 & 11 \\
\hline $11 / 17$ & 6 & 0 & 2 & 2 & 1 & 2 & 1 & 0 & 3 & 1 & 2 & 2 & 2 & 1 & 7 & 0 & 10 & 1 & 3 & 0 & 37 & 9 \\
\hline $11 / 18$ & 6 & 1 & 3 & 1 & 1 & 2 & 1 & 1 & 4 & 1 & 2 & 0 & 2 & 0 & 5 & 1 & 7 & 3 & 3 & 0 & 34 & 10 \\
\hline $11 / 19$ & 3 & 0 & 1 & 1 & 1 & 1 & 1 & 0 & 4 & 0 & 1 & 1 & 2 & 0 & 4 & 0 & 4 & 0 & 1 & 0 & 22 & 3 \\
\hline $11 / 20$ & 3 & 0 & 1 & 1 & 1 & 1 & 0 & 1 & 2 & 1 & 1 & 0 & 2 & 1 & 3 & 0 & 4 & 1 & 1 & 0 & 18 & 6 \\
\hline total & 106 & 7 & 67 & 23 & 70 & 51 & 18 & 24 & 92 & 30 & 53 & 29 & 44 & 21 & 138 & 13 & 206 & 56 & 61 & 6 & 855 & 260 \\
\hline
\end{tabular}

\section{REFERENCES}

1. Abd-Alla, A. M., Abo-Dahab, S. M., Hammad, H. A., and Mahmoud, S. R., "On generalized magneto-thermoelastic rayleigh waves in a granular medium under the influence of a gravity field and initial stress," Journal of Vibration and Control, Vol. 17, No. 1, pp. 115-128 (2011).

2. Ahmadian, H. and Azizi, H., "Stability analysis of a nonlinear jointed beam under distributed follower force," Journal of Vibration and Control, Vol. 17, No. 1, pp. 27-38 (2011).

3. Chen, C. W., "Stability conditions of fuzzy systems and its application to structural and mechanical systems," Advances in Engineering Software, Vol. 37, pp. 624-629 (2006)

4. Chen, C. W., "Modeling and control for nonlinear structural systems via a NN-based approach, "Expert Systems with Applications, Vol. 36, pp. 4765 4772 (2009).

5. Chen, C. W., "The stability of an oceanic structure with T-S fuzzy models,"
Mathematics and Computers in Simulation, Vol. 80, pp. $402-426$ (2009).

6. Chen, C. W., "Modeling and fuzzy PDC control and its application to an oscillatory TLP structure," Mathematical Problems in Engineering- An Open Access Journal, DOI: 10.1155/2010/120403 (2010).

7. Chen, C. W., "Application of fuzzy-model-based control to nonlinear structural systems with time delay: an LMI method," Journal of Vibration and Control, Vol. 16, pp. 1651-1672 (2010).

8. Chen, C. W., "Modeling, control and stability analysis for time-delay TLP systems using the fuzzy Lyapunov method," Neural Computing and Applications, Vol. 20, No. 4, pp. 527-534 (2011).

9. Chen, C. W., "Stability analysis and robustness design of nonlinear systems: an NN-based approach," Applied Soft Computing, Vol. 11, No. 2, pp. 2735-2742 (2011)

10. Chen, C. W., "A critical review of parallel distributed computing and the Lyapunov criterion for multiple time-delay fuzzy systems," International Journal of the Physical Sciences, Vol. 6, No. 19, pp. 4492-4501 (2011). 
11. Chen, C. W., "Internet services and interface design for marketing: a preliminary study of Cliven products," International Journal of the Physical Sciences, Vol. 6, No. 15, pp. 3585-3596 (2011).

12. Chen, C. W., "Fuzzy control of interconnected structural systems using the fuzzy Lyapunov method," Journal of Vibration and Control, Vol. 17, No. 11, pp. 1693-1702 (2011)

13. Chen, C. W., "Applications of LDI-based criterion to a nonlinear chaotic system: a critical review," Journal of Vibration and Control (accepted).

14. Chen, C. W., "Applications of the fuzzy Lyapunov LMI criterion to a chaotic structural system," Journal of Vibration and Control (accepted).

15. Chen, C. W., "Delay independent criterion for multiple time-delay systems and its application in building structure control systems," Journal of Vibration and Control, DOI: 10.1177/1077546311429341 (2012).

16. Chen, C. W., "Applications of linear differential inclusion-based criterion to a nonlinear chaotic system: a critical review," Journal of Vibration and Control, DOI: 10.1177/1077546311428345 (2012).

17. Chen, C. W., "Applications of the fuzzy Lyapunov linear matrix inequality criterion to a chaotic structural system," Journal of Vibration and Control, DOI: 10.1177/1077546311428346 (2012).

18. Chen, C. W., Chang, M. L., and Tseng, C. P., "The human factors of knowledge sharing intention among Taiwanese enterprises: a model of hypotheses," Human Factors and Ergonomics in Manufacturing \& Service Industries, DOI: 10.1002/hfm.20286 (2012).

19. Chen, C. W., Chang, M. L., and Tseng, C. P., "Critical human factor evaluation of knowledge sharing intention in Taiwanese enterprises," Human Factors and Ergonomics in Manufacturing \& Service Industries, DOI: 10.1002/hfm.20300 (2012).

20. Chen, C. W. and Chen, P. C., "GA-based adaptive neural network controllers for nonlinear systems," International Journal of Innovative Computing, Information and Control, Vol. 6, pp. 1793-1803 (2010).

21. Chen, C. W., Chen, P. C., and Chiang, W. L., "Stabilization of adaptive neural network controllers for nonlinear structural systems using a singular perturbation approach," Journal of Vibration and Control, Vol. 17, No. 8, pp. 1241-1252 (2011).

22. Chen, C. W., Chen, T. H., and Lin, Y. F., "The statistical analysis for consumers' intensions of purchasing cosmetics," African Journal of Business Management, Vol. 5, No. 29, pp. 11630-11635 (2011)

23. Chen, C. W., Chiang, W. L., and Hsiao, F. H., "Stability analysis of T-S fuzzy models for nonlinear multiple time-delay interconnected systems,' Mathematics and Computers in Simulation, Vol. 66, pp. 523-537 (2005).

24. Chen, C. W., Chiang, W. L., and Tsai, C. H., "Fuzzy Lyapunov method for stability conditions of nonlinear systems," International Journal on Artificial Intelligence Tools, Vol. 15, pp. 163-171 (2006).

25. Chen, C. W., Lee, K. L., and Tseng, C. P., "The relationship between personality traits and sales force automation usage: a preliminary study,' Human Factors and Ergonomics in Manufacturing \& Service Industries (accepted).

26. Chen, C. W., Lin, C. L., and Tsai, C. H., "A novel delay-dependent criteria for time-delay T-S fuzzy systems using fuzzy Lyapunov method," International Journal on Artificial Intelligence Tools, Vol. 16, pp. 545-552 (2007).

27. Chen, C. W., Shen, C. W., and Jeng, M. J., "Stability analysis of an oceanic structure using the Lyapunov method," Engineering Computations, Vol. 27, pp. 186-204 (2010).

28. Chen, C. W., Tseng, C. P., Lee, K. L., and Yang, H. C., "Conceptual framework and research method for personality traits and sales force automation usage," Scientific Research and Essays, Vol. 6, No. 17, pp. 3784-3793 (2011).

29. Chen, C. W., Wang, M. H. L., and Lin, J. W., "Managing target the cash balance in construction firms using a fuzzy regression approach," International Journal of Uncertainty, Fuzziness and Knowledge-Based Systems, Vol. 17, pp. 667-684 (2009).

30 Chen, C. W., Wang, H. L., Liu, F. R., and Chen, T. H., "Application of project cash management and control for infrastructure," Journal of Marine Science and Technology, Vol. 18, pp. 644-651 (2010).

31. Chen, C. W., Yang, P. H. C., Chang A. K. H., and Chen, T. H., "Evaluation of inference adequacy in cumulative logistic regression models: an empirical validation of ISW-ridge relationships," China Ocean Engineering, Vol. 22, pp. 43-56 (2008).

32. Chen, C. W., Yang, H. C., and Chen, T. H., "Analysis of experimental data on internal waves with statistical method," Engineering Computations International Journal for Computer-Aided Engineering and Software, Vol. 24, pp. 116-150 (2007).

33. Chen, C. W., Yeh, K., Chiang, W. L., and Wu, D. J., "Modeling, $\mathrm{H}^{\infty}$ control and stability analysis for structural systems using Takagi-Sugeno fuzzy model," Journal of Vibration and Control, Vol. 13, pp. 1519-1534 (2007).

34. Chen, C. W., Yeh, K., and Liu, F. R., "Adaptive fuzzy sliding mode control for seismically excited bridges with lead rubber bearing isolation," International Journal of Uncertainty, Fuzziness and KnowledgeBased Systems, Vol. 17, pp. 705-727 (2009).

35. Chen, C. W., Yeh, K., Liu, K. F. R., and Lin, M. L., “Applications of fuzzy control to nonlinear time-delay systems using the linear matrix inequality fuzzy Lyapunov method," Journal of Vibration and Control, DOI: 10.1177/1077546311410765 (2012)

36. Chen, C. Y., "Using discriminant analysis to determine the breaking criterion for an ISW propagating over a ridge," Environmental Fluid Mechanics, Vol. 10, pp. 77-586 (2010).

37. Chen, C. Y., "A critical review of internal wave dynamics. Part 2 Laboratory experiments and theoretical physics," Journal of Vibration and Control, DOI: 10.1177/1077546310397561 (2011).

38. Chen, C. Y., "A critical review of internal wave dynamics. Part 1 - Remote sensing and in-situ observations," Journal of Vibration and Control, Vol. 18, No. 3, pp. 417-436, DOI: 10.1177/1077546310395971 (2011).

39. Chen, C. Y., "Statistical and dynamical analyses of propagation mechanisms of solitary internal waves in a two-layer stratification," Journal of Marine Science and Technology, Vol. 16, No. 1, pp. 100-114, DOI: 10.1007/s00773-010-0112-z (2011).

40. Chen, C. Y., "A critical review and improvement method on biped robot," International Journal of Innovative Computing, Information and Control, Vol. 7, No. 9, pp. 5245-5254 (2011).

41. Chen, C. Y., "An innovative knowledge management learning cycle by Lego NXT for science education," International Journal of Innovative Computing, Information and Control, Vol. 8, No. 1B, pp. 791-798 (2012).

42. Chen, C. Y., "A critical review of internal wave dynamics. Part 1 - Remote sensing and in-situ observations," Journal of Vibration and Control, Vol. 18, No. 3, pp. 417-436, DOI: 10.1177/1077546310395971 (2012).

43. Chen, C. Y., "Assessment of the major hazard potential of interfacial solitary waves moving over a trapezoidal obstacle on a horizontal plateau," Natural Hazards, DOI: 10.1007/s11069-012-0107-7 (2012).

44. Chen, C. Y., "Internal wave transport, nonlinear manifestation, and mixing in a stratified shear layer- technical briefs," Journal of Vibration and Control, DOI: 10.1177/1077546311429337 (2012).

45. Chen, C. Y. and Hsu, J. R. C., "Fuzzy logic derivation of neural network models with time delays in subsystems," International Journal on Artificial Intelligence Tools, Vol. 14, pp. 967-974 (2005).

46. Chen, C. Y. and Hsu, J. R. C., "Generation of internal solitary wave by gravity collapse," Journal of Marine Science and Technology, Vol. 15, pp. 1-7 (2007).

47. Chen, C. Y. and Hsu, J. R. C., "Wave propagation at the interface of a two-layer fluid system in the laboratory," Journal of Marine Science and Technology, Vol. 15, pp. 8-16 (2007).

48. Chen, C. Y., Hsu, J. R. C., and Cheng, M. H., "Numerical model of an internal solitary wave evolution on impermeable variable seabed in a stratified two-layer fluid system," China Ocean Engineering, Vol. 20, pp. 303-313 (2006).

49. Chen, C. Y., Hsu, J. R. C., and Cheng, M. H. "Experiments on mixing and dissipation in internal solitary waves over two triangular obstacles," Environmental Fluid Mechanics, Vol. 8, pp. 199-214 (2008).

50. Chen, C. Y. and Huang, P. H., "Review of an autonomous humanoid robot and its mechanical control," Journal of Vibration and Control, DOI: 10.1177/1077546310395974 (2011) 
51. Chen, C. Y., Lee, W. I., Kuo, H. M., and Chen, K. H., "The study of a forecasting sales model for fresh food," Expert Systems with Applications, Vol. 37, pp. 7696-7702 (2010).

52. Chen, C. Y., Lin, C. L., and Tseng, I. F., "Dynamic behavior of an internal solitary wave oscillating over variable bathymetry," Kuwait Journal of Science \& Engineering, Vol. 34, pp.153-166 (2007).

53. Chen, C. Y., Lin, J. W., and Lee, W. I. "Fuzzy control for an oceanic structure: A case study in time-delay TLP system," Journal of Vibration and Control, Vol. 16, pp. 147-160 (2010).

54. Chen, C. Y., Liu, K. C., Liu, Y. W., and Huang, W. C., "A case study of reinforced concrete short column under earthquake using experimental and theoretical investigations," Structural Engineering and Mechanics, Vol. 36, pp. 197-206 (2010)

55. Chen, C. Y., Shen, C. W., Chen, C. W., Liu, K. F. R., and Jeng, M. J., “A stability criterion for time-delay tension leg platform systems subjected to external force," China Ocean Engineering, Vol. 23, pp. 49-57 (2009).

56. Chen, C. Y., Shih, B. Y., Chen, Z. S., and Chen, T. H., "The exploration of internet marketing strategy by search engine optimization: A critical review and comparison," African Journal of Business Management, Vol. 5, No. 12, pp. 4644-4649 (2011)

57. Chen, C. Y., Shih, B. Y., and Chou, W. C., "Obstacle avoidance design for a humanoid intelligent robot with ultrasonic sensors," Journal of Vibration and Control, Vol. 17, No. 12, pp. 1798-1804, DOI: 10.1177/1077546310381101 (2011).

58. Chen, C. Y., Shih, B. Y., and Chou, W. C., "An enhanced obstacle avoidance and path correction mechanism for an autonomous intelligent robot with multiple sensors," Journal of Vibration and Control, DOI: 10.1177/1077546311426734 (2012).

59. Chen, C. Y., Shih, B. Y., and Ma, J. M., "Development for low-cost and cross-platform robot control environment," Journal of Vibration and Control, DOI: 10.1177/1077546311430107 (2012).

60. Chen, C. Y., Shih, B. Y., Shih, C. H., and Chou, W. C., "The development of autonomous low cost biped mobile surveillance robot by intelligent bricks," Journal of Vibration and Control, DOI: 10.1177/1077546310371349 (2011).

61. Chen, C. Y., Shih, B. Y., Shih, C. H., and Wang, L. H., "Design, modeling and stability control for an actuated dynamic walking planar bipedal robot," Journal of Vibration and Control, DOI: 10.1177/1077546311429476 (2012)

62. Chen, C. Y., Shih, B. Y., Shih, C. H., and Wang, L. H., "Human-machine interface for the motion control of humanoid biped robots using a graphical user interface Motion Editor," Journal of Vibration and Control, DOI: 10.1177/1077546312437804 (2012).

63. Chen, C. Y., Shyue, S. W., and Chang, C. J., "Association rule mining for evaluation of regional environments: Case study of Dapeng Bay, Taiwan," International Journal of Innovative Computing, Information and Control, Vol. 6, pp. 3425-3436 (2010).

64. Chen, C. Y. and Tsen, I. F., "Localized mixing due to an interfacial solitary wave breaking on seabed topography in different ridge heights," Journal of Offshore Mechanics and Arctic Engineering, Vol. 129, pp. 245-250 (2007).

65. Chen, C. Y., Tseng, I. F., Yang, H. C. P., and Chen, T. H., "Profile evolution and energy dissipation for internal soliton transmitting over different submarine ridges," China Ocean Engineering, Vol. 20, pp. 585-594 (2006)

66. Chen, C. Y., Yang, H. C., and Chen, T. H., "Diagnosing and revising logistic regression models: effect on internal solitary wave propagation,' Engineering Computations-International Journal for Computer-Aided Engineering and Software, Vol. 25, pp. 121-139 (2008).

67. Chen, C. Y., Yang, Y. F., Chen, L. T., and Chen, T. H., "Linking the balanced scorecard (BSC) to business management performance: A preliminary concept of fit theory for navigation science and management,' International Journal of the Physical Sciences, Vol. 5, pp. 1296-1305 (2010).

68. Chen, L. T., "Are educational background and gender moderator variables for leadership, satisfaction and organizational commitment," African Journal of Business Management, Vol. 4, pp. 248-261 (2010).

69. Chen, P. C. and Chiang, W. L., "GA-based fuzzy sliding mode controller for nonlinear systems," Mathematical Problems in Engineering- An Open Access Journal, DOI: 10.1155/2008/325859 (2008).

70. Chen, P. C. and Chiang, W. L., "GA-based modified adaptive fuzzy sliding mode controller for nonlinear systems," Expert Systems with Applications, Vol. 36, pp. 5872-5879 (2009).

71. Chen, P. C. and Chiang, W. L., "Linear matrix inequality conditions of nonlinear systems by genetic algorithm-based adaptive fuzzy sliding mode controller," Journal of Vibration and Control, Vol. 17, No. 2, pp. 163 173 (2011)

72. Chen, P. C., Chiang, W. L., and Lo, D. C., "GA-based decoupled adaptive FSMC for nonlinear systems by a singular perturbation scheme," Neural Computing and Applications, Vol. 20, No. 4, pp. 517-526 (2011).

73. Chen, P. C., Chiang, W. L., and Yeh, K., "A novel stability condition and its application to GA-based fuzzy control for nonlinear systems with uncertainty," Journal of Marine Science and Technology, Vol. 17, pp. 293-299 (2009)

74. Chen, T. H., "Application of data mining to the spatial heterogeneity of foreclosed mortgages," Expert Systems with Applications, Vol. 37, pp. 993-997 (2010)

75. Chen, T. H. and Yang, C. H. "A mathematical tool for inference in logistic regression with small-sized data sets - A Practical Application on ISWRidge Relationships," Mathematical Problems in Engineering- An Open Access Journal, DOI: 10.1155/2008/186372 (2008).

76. Chen, T. H. and Yang, H. C., "Application of logistic regression model: propagation effect on internal soliton," Journal of Chung Cheng Institute of Technology, Vol. 37, pp. 1-10 (2009).

77. Chen, W. T. and Saif, M., "Fuzzy nonlinear unknown input observer design with fault diagnosis applications," Journal of Vibration and Control, Vol. 16, No. 3, pp. 377-401 (2010).

78. Cheng, M. H. and Hsu J. R. C., "Laboratory experiments on waveform inversion of an internal solitary wave over a slope-shelf," Environmental Fluid Mechanics, Vol. 11, No. 4, pp. 353-384 (2011).

79. Chiang, T. C. and Wang, W. J., "Highway on-ramp control using fuzzy decision making," Journal of Vibration and Control, Vol. 17, No. 2, pp. 205-213 (2011).

80. Chiang, W. L., Chiou, D. J., Tang, J. P., Hsu, W. K., and Liu, T. Y., "Detecting the sensitivity of structural damage based on the Hilbert-Huang transform approach," Engineering Computations, Vol. 27, pp. 799-818 (2010).

81. Chiou, D. J., Hsu, W. K., Chen, C. W., Hsieh, C. M., Tang, J. P., and Chiang, W. L., "Applications of Hilbert-Huang transform to structural damage detection," Structural Engineering and Mechanics, Vol. 39, No. 1, pp. 1-20 (2011)

82. Chu, T. H., Lin, M. L., and Chang, C. H., "Developing a tour guiding information system for tourism service using mobile GIS and GPS techniques," Advances in Information Sciences and Service Sciences, Vol. 3, No. 6, pp. 49-58 (2011).

83. Cross, S. S., Harrison, R. F., and Kennedy, R. L., "Introduction to neural networks," Lancet, Vol. 346, pp. 1075-1079 (1995).

84. Diamantopoulos, A. and Winklhofer, H., "Export sales forecasting by UK firms technique utilization and impact on forecast accuracy," Journal of Business Research, Vol. 56, pp. 45-54 (2003).

85. Doganis, P., Alexandridis, A., Patrinos, P., and Sarimveis, H., "Time series sales forecasting for short shelf-life food products based on artificial neural networks and evolutionary computing," Journal of Food Engineering, Vol. 75, pp. 196-204 (2006).

86. Dreiseitl, S. and Ohno-Machado, L., "Logistic regression and artificial neural network classification models: a methodology review," Journal of Biomedical Informatics, Vol. 35, No. 5-6, pp. 352-359 (2002).

87. Eguchi, K., Itoh, Y., and Konishi, T., "A drawing-aid system based on a fuzzy scheme," International Journal of Innovative Computing, Information and Control, Vol. 3, No. 4, pp. 3047-3058 (2007).

88. Fildes, R. and Hastings, R., "The organization and improvement of market forecasting," Journal of the Operational Research Society, Vol. 45, pp. 1-16 (1994).

89. Horimoto, Y., Lee, K., and Nakai, S., "Classification of microbial defects in milk using a dynamic headspace gas chromatograph and computer- 
aided data processing. 2. Artificial neural networks, partial least-squares regression analysis, and principal component regression analysis," Journal of Agricultural and Food Chemistry, Vol. 45, No. 3, pp. 743-747 (1997).

90. Hsiao, F. H., Chen, C. W., Liang, Y. W., Xu, S. D., and Chiang, W. L., "T-S fuzzy controllers for nonlinear interconnected systems with multiple time delays," IEEE Transactions on Circuits \& Systems-I: Regular Papers, Vol. 52, pp. 1883- 1893 (2005).

91. Hsiao, F. H., Chen, C. W., Wu, Y. H., and Chiang, W. L., "Fuzzy controllers for nonlinear interconnected TMD systems with external force," Journal of the Chinese Institute of Engineers, Vol. 28, pp. 175-181 (2005).

92. Hsiao, F. H. and Chiang, W. L., "Fuzzy control for nonlinear systems via neural-network-based approach," International Journal for Computational Methods in Engineering Science and Mechanics, Vol. 6, pp. 145 152 (2005).

93. Hsiao, F. H., Chiang, W. L., Chen, C. W., Xu, S. D., and Wu, S. L., "Application and robustness design of fuzzy controller for resonant and chaotic systems with external disturbance" International Journal of Uncertainty, Fuzziness and Knowledge-Based System, Vol. 13, pp. 281-295 (2005)

94. Hsiao, F. H., Hwang, J. D., and Tsai, Z. R., "Robust stabilization of nonlinear multiple time-delay large-scale systems via decentralized fuzzy control," IEEE Trans. Fuzzy Systems, Vol. 13, pp. 152- 163 (2005)

95. Hsieh, T. Y. and Wang, M. H. L., "A new viewpoint of S-curve regression model and its application to construction management," International Journal on Artificial Intelligence Tools, Vol. 15, pp. 131-142 (2006).

96. Hsu, W. K., Huang, P. C., Chang, C. C., Hung, D. M., and Chiang, W. L., "An integrated flood risk assessment model for property insurance industry in Taiwan," Natural Hazards, Vol. 58, No. 3, pp. 1295-1309 (2011).

97. Jayaswal, P., Verma, S. N., and Wadhwani, A. K., "Development of EBP-Artificial neural network expert system for rolling element bearing fault diagnosis," Journal of Vibration and Control, Vol. 17, No. 8, pp. 1131-1148 (2011).

98. Kuo, H. M., "Application of quality function deployment to improve the quality of Internet shopping website interface design," International Journal of Innovative Computing, Information and Control, Vol. 7, No. 1 , pp. 253-268 (2011).

99. Kuo, H. M., "A study of merchandise information and interface design on B2C websites," Journal of Marine Science and Technology, Vol. 19, No. 1, pp. 15-25 (2011).

100. Kuo, H. M., "A novel viewpoint on information and interface design for auction website," Human Factors and Ergonomics in Manufacturing \& Service Industries, DOI: 10.1002/hfm.20274 (2012).

101. Kuo, H. M., "A study of B2C supporting interface design system for the elderly," Human Factors and Ergonomics in Manufacturing \& Service Industries, DOI: 10.1002/hfm.20297 (2012).

102. Lee, S. C., Lin, P. H., Wang, J. S., Huang, C. H., and Huang, P. H., "Mass media in Taiwan and the formation of Chien-Ming Wang's baseball superstar image," International Journal of the Physical Sciences, Vol. 6, pp 3000-3006 (2011).

103. Lee, S. C., Wang, C. C., Huang, C. C., Wang, J. S., Huang, C. H., and Huang, P. H., "The idolization of Chien-Ming Wang and social psychological factors in Taiwan," International Journal of the Physical Sciences, Vol. 6, pp. 2607-2612 (2011).

104. Lee, W. I., "The development of a qualitative dynamic attribute value model for healthcare institutes," Iranian Journal of Public Health, Vol. 39, No. 4, pp. 15-25 (2010).

105. Lee, W. I., "A forecasting model for fresh food sales in POS database: a comparison between the logistic regression, moving average and BPNN methods," Journal of Marine Science and Technology (accepted).

106. Lee, W. I., Chen, T. H., and Chen, C. Y., "The relationship between consumer orientation, service value, medical care service quality and patient satisfaction: The case of a medical center in Southern Taiwan," African Journal of Business Management, Vol. 4, pp. 448-458 (2010).

107. Lee, W. I., Chiu, Y. T., Liu, C. C., and Chen, C. Y., "Assessing the effects of consumer involvement and service quality in a self-service setting," Human Factors and Ergonomics in Manufacturing \& Service Industries, Vol. 21, No. 5, pp. 504-515, DOI: 10.1002/hfm.20253 (2011).

108. Lee, W. I. and Wu, C. H., "Relationship between quality of medical treatment and customer satisfaction - a case study in dental clinic association," International Journal of Innovative Computing, Information and Control, Vol. 6, pp. 1805-1822 (2010).

109. Li, C.H. and Park, S.C., "Combination of modified BPNN algorithms and an efficient feature selection method for text categorization," Information Processing and Management, Vol. 45, pp. 329-340 (2009).

110. Li, L., Song, G., and Ou, J., "Nonlinear structural vibration suppression using dynamic neural network observer and adaptive fuzzy sliding mode control," Journal of Vibration and Control, Vol. 16, No. 10, pp. 1503 1526 (2010).

111. Lin, C. H., "Using neural networks as a support tool in the decision making for insurance industry," Expert Systems with Applications, Vol. 36, No. 3, pp. 6914-6917 (2009).

112. Lin, C. L., Wang, J. F., Chen, C. Y., and Yen, C. W., "Improving the generalization performance of RBF neural networks using a linear regression technique," Expert Systems with Applications, Vol. 36, pp. 1204912053 (2009).

113. Lin, J. W. and Chung, S. H., "Modeling and assessment of bridge structure for seismic hazard prevention," Natural Hazards, DOI: 10.1007/s11069-011-9969-3 (2011).

114. Lin, J. W. and Hsu, T. C., "Fuzzy statistical refinement for the forecasting of tenders for roadway construction," Journal of Marine Science and Technology (accepted).

115. Lin, J. W., Huang, C. W., Shih, C. H., and Chen, C. Y., "Fuzzy Lyapunov stability analysis and NN modeling for tension leg platform systems,' Journal of Vibration and Control, Vol. 17, No. 2, pp. 151-158 (2011).

116. Lin, J. W. and Peng, C. Y., "Kalman filter decision systems for debris flow hazard assessment," Natural Hazards, Vol. 60, No. 3, pp. 12551266, DOI: 10.1007/s11069-011-9907-4 (2012).

117. Lin, M. L., "Application of fuzzy models for the monitoring of ecologically sensitive ecosystems in a dynamic semi-arid landscape from satellite imagery," Engineering Computations, Vol. 27, pp. 5-19 (2010).

118. Lin, M. L., "Using GIS-based spatial geocomputation from remotely sensed data for drought risk-sensitive assessment," International Journal of Innovative Computing, Information and Control, Vol. 7, No. 2, pp. 657-668 (2011).

119. Lin, M. L., "Stability analysis of community and ecosystem hierarchies using the Lyapunov method," Journal of Vibration and Control, Vol. 17, No. 13, pp. 1930-1937, DOI: 10.1177/1077546310385737 (2012).

120. Lin, M. L., Wang, Q. B., and Cao, Y., "Fuzzy model-based assessment and monitoring of desertification using MODIS satellite imagery," Engineering Computations, Vol. 26, pp. 745-760 (2009).

121. Liu, K. C., Liu, Y. W., and Huang, W. C., "The structure behavior of reinforced concrete wing-wall under earthquake," International Journal of the Physical Sciences, Vol. 5, No. 7, pp. 1164-1174 (2010).

122. Liu, K. C., Liu, Y. W., and Huang, W. C., "Nonlinear vibration of structural deterioration in reinforced concrete columns: experimental and theoretical investigation," Journal of Vibration and Control, DOI: 10.1177/1077546311429477 (2012).

123. Liu, K. F. R., Hsu, C. Y., and Yeh, K., "Hierarchical analytic network process and its application in environmental impact evaluation," Civil Engineering and Environmental Systems, Vol. 28, No. 1, pp. 1-18 (2011).

124. Liu, K. F. R., Lu, C. F., and Shen, Y. S., "Applying Bayesian belief networks to health risk assessment," Stochastic Environmental Research \& Risk Assessment, Vol. 26, No. 3, pp. 451-465, DOI: 10.1007/s00477-011-0470-z (2012).

125. Liu, T. Y., Chiang, W. L., Hsu, W. K., Lin, C. W., Huang, P. C., and Chu, T. J., "Structural system identification for vibration bridges using the Hilbert-Huang transform," Journal of Vibration and Control, DOI: $10.1177 / 1077546311428347$ (2012).

126. Liu, T. Y., Chiang, W. L., Hsu, W. K., Lu, L. C., and Chu, T. J., "Identification and monitoring of bridge health from ambient vibration data," 
Journal of Vibration and Control, Vol. 17, No. 4, pp. 589-603 (2011).

127. Makridakis, S. and Wheelwright, S. C., In Forecasting Methods for Management, 5th Ed., Wiley, Chichester (1989).

128. Makridakis, S., Wheelwright, S. C., and Hyndman, R. J., Forecasting Methods and Applications, 3rd Ed., Wiley, New York (1998).

129. Marichal, G. N., Artes, M., and Garcia, P. J. C., "An intelligent system for faulty-bearing detection based on vibration spectra," Journal of $\mathrm{Vi}$ bration and Control, Vol. 17, No. 6, pp. 931-942 (2011).

130. Mentzer, J. T. and Bienstock, C. C., Sales Forecasting Management: Understanding the Techniques, Systems and Management of the Sales Forecasting Process, Sage publications, Thousand Oaks, CA (1998).

131. Metin, M. and Guclu, R., "Active vibration control with comparative algorithms of half rail vehicle model under various track irregularities," Journal of Vibration and Control, Vol. 17, No. 10, pp. 1525-1539 (2011).

132. Paruelo, J. M. and Tomasel, F., "Prediction of functional characteristics of ecosystems: a comparison of artificial neural networks and regression models," Ecology Model, pp. 173-186 (1998)

133. Pindyck, R. S. and Rubinfeld, D. L., Econometric Models and Economic Forecasts, 4th Ed., McGraw-Hill (1998).

134. Rumelhart, D., Hinton, G., and Williams, R., "Learning representations by back-propagating errors," Nature, Vol. 323, pp. 533-536 (1986).

135. Sargent, D. J. "Comparison of artificial neural networks with other statistical approaches: results from medical data sets," Cancer Center Statistics, Vol. 91, pp. 1636-1642 (2001).

136. Shen, C. W., Cheng, M. J., Tsai, F. M., and Cheng, Y. C., "A fuzzy AHP-based fault diagnosis for semiconductor lithography process," International Journal of Innovative Computing, Information and Control, Vol. 7, No. 2, pp. 805-816 (2011).

137. Shih, B. Y., Chang, C. J., and Chen, A. W., "Enhanced MAC channel selection to improve performance of IEEE 802.15.4," International Journal of Innovative Computing, Information and Control, Vol. 6, pp. 5511-5526 (2010).

138. Shih, B. Y., Chen, C. Y., Chang, H., and Ma, J. M., "Dynamics and control for robot manipulators using a greedy algorithm approach," Journal of Vibration and Control, DOI: 10.1177/1077546311407649 (2011).

139. Shih, B. Y. and Chou, W. C., "Obstacle avoidance using a path correction method for autonomous control of a biped intelligent robot," Journal of Vibration and Control, Vol. 17, No. 10, pp. 1567-1573, DOI 10.1177/1077546310372004 (2011).

140. Shih, B. Y., Lee, W. I., and Chen, C. Y., "A hybrid artificial intelligence sales-forecasting system in the convenience store industry," Human Factors and Ergonomics in Manufacturing \& Service Industries, DOI: 10.1002/hfm.20272 (2011)

141. Shih, B. Y. and Li, C. E., "The exploration of mobile mandarin learning system by the application of TRIZ theory," Computer Applications in Engineering Education, DOI: 10.1002/cae.20478 (2011).

142. Shih, B. Y., Lo, T. W., and Chen, C. Y., "The research of quadtree search algorithms for anti-collision in radio frequency identification systems," Scientific Research and Essays, Vol. 6, No. 25, pp. $5342-5350$ (2011).

143. Shih, B. Y., Shih, C. H., Li, C. C., Chen, T. H., Chen, Y. H., and Chen, C. Y., "Elementary school student's acceptance of Lego NXT: The technology acceptance model, a preliminary investigation," International Journal of the Physical Sciences, Vol. 6, No. 22, pp. 5054-5063 (2011).

144. Shih, B. Y., Shih, C. H., and Tseng, J. Y., "The development of enhancing mechanisms for improving the performance of IEEE 802.15.4," International Journal of the Physical Sciences, Vol. 5, pp. 884-897 (2010).

145. Shih, C. H., Wakabayashi, N., Yamamura, S., and Chen, C. Y., "A context model with a time-dependent multi-layer exception handling policy," International Journal of Innovative Computing, Information and Control, Vol. 7, No. 5A, pp. 2225-2234 (2011)

146. Shih, C. H. and Yamamura, S., "Analysis of control structure for turning maneuvers," Mathematical Problems in Engineering 2010, DOI: 10.1155/2010/481438 (2010).

147. Solihin, M. I., Wahyudi, and Legowo, A., "Fuzzy-tuned PID anti-swing control of automatic gantry crane," Journal of Vibration and Control,
Vol. 16, No. 1, pp. 127-145 (2010).

148. Soundarrajan, A. and Sumathi, S., "Fuzzy-based intelligent controller for power generating systems," Journal of Vibration and Control, Vol. 17, No. 8, pp. 1265-1278 (2011)

149. Starett, S. K. and Adams, G. L., "Using artificial neural networks and regression to predict percentage of applied nitrogen leached under turfgrass," Communications in Soil Science \& Plant Analysis, Vol. 28, No. 6-8, pp. 497-507 (1997).

150. Su, T. J., Cheng, J. C., Huang, M. Y., and Lin, T. H. "Applications of cellular neural networks to noise cancellation in gray images based on adaptive particle swarm optimization," Circuits, Systems, and Signal Processing, Vol. 30, No. 6, pp. 1131-1148, DOI: 10.1007/s00034-011-9269-x (2011).

151. Tang, J. P., Chiou, D. J., Chiang, W. L., Hsu, W. K., and Liu, T. Y., “A case study of damage detection in benchmark buildings using a Hilbert-Huang Transform-based method," Journal of Vibration and Control, Vol. 17, No. 4, pp. 623-636 (2011).

152. Tsai, C. H., "The establishment of a rapid natural disaster risk assessment model for the tourism industry," Tourism Management, Vol. 32, No. 1, pp. 158-171 (2011).

153. Tsai, C. H., "Development of a mechanism for typhoon and flood risk assessment and disaster management in the hotel industry - a case study of the Hualien area," Scandinavian Journal of Hospitality and Tourism, Vol. 11, No. 3, pp. 324-341 (2011).

154. Tsai, C. H., Chiang, W. L., and Lin, M. L., "Application of geographic information system to the allocation of disaster shelters via fuzzy models," Engineering Computations-International Journal for ComputerAided Engineering and Software, Vol. 25, pp. 86-100 (2008).

155. Tseng, C. P., "Natural disaster management mechanisms for probabilistic earthquake loss," Natural Hazards, Vol. 60, No. 3, pp. 1055-1063, DOI: 10.1007/s11069-011-9889-2 (2012).

156. Tseng, C. P. and Chang, M. L., "The human factors of knowledge sharing intention among Taiwanese enterprises: a preliminary study," Human Factors and Ergonomics in Manufacturing \& Service Industries, DOI: 10.1002/hfm.20284 (2012).

157. Tseng, C. P. and Liu, F. R., "Risk control allocation model for pressure vessels and piping project," Journal of Vibration and Control, Vol. 18, No. 3, pp. 385-394, DOI: 10.1177/1077546311403182 (2012).

158. Tseng, C. P. and Tu, Y. P., "A new viewpoint on risk control decision models for natural disasters," Natural Hazards, Vol. 59, No. 3, pp. 1715 1733, DOI: 10.1007/s11069-011-9861-1 (2012).

159. Winklhofer, H. and Diamantopoulos, A., "A model of export sales forecasting behavior and performance: development and testing," International Journal of Forecasting, Vol. 19, pp. 271-285 (2003).

160. Wood, D. and Dasgupta, B., "Classifying trend movements in the MSCI U.S.A. capital market index-a comparison of regression, aroma and neural network methods," Computers \& Operations Research, Vol. 23, No. 6, pp. 611-622 (1996).

161. Wu, C. H., "Behavior-based spam detection using a hybrid method of rule-based techniques and neural networks," Expert Systems with Applications, Vol. 36, No. 3, pp. 4321-4330 (2009).

162. Yang, H. C., "Potential hazard analysis from the viewpoint of flow measurement in large open-channel junctions," Natural Hazards, Vol. 61, No. 2, pp. 803-813 (2012).

163. Yang, H. C., Chen, C. Y., and Chen, T. H., "Estimation on internal wave reflection in a two-layer fluid system by cumulative logistic regression model," Journal of Marine Science and Technology, Vol. 16, pp. 44-51 (2008).

164. Yang, H. C., Chen, T. H., and Liu, C. T., "Accuracy evaluation of a diagnostic test by detecting outliers and influential observations," China Ocean Engineering, Vol. 22, pp. 421-429 (2008).

165. Yeh, K. and Chen, C. Y., "Robustness design of time-delay fuzzy systems using fuzzy Lyapunov method," Applied Mathematics and Computation, Vol. 205, pp. 568-577 (2008)

166. Yeh, K., Lo, D. C., and Liu, K. F. R., "Neural-network fuzzy control for chaotic tuned mass damper systems with time delays," Journal of Vi- 
bration and Control, DOI: 10.1177/1077546311407538 (2012).

167. Yu, S. E. S., Huarng, K. H., Li, M. Y. L., and Chen, C. Y., "A novel option pricing model via fuzzy binomial decision tree," International Journal of Innovative Computing, Information and Control, Vol. 7, No. 2 pp. 709-718 (2011).

168. Yu, S. E., Li, M. Y. L., Huarng, K. H., Chen, T. H., and Chen, C. Y., "Model construction of option pricing based on fuzzy theory," Journal of Marine Science and Technology, Vol. 19, No. 5, pp. 460-469 (2011).

169. Zhang, H. N. J. and Ni, X., "Internal energy based analysis on mechanism of spindle speed variation for regenerative chatter control," Journal of Vibration and Control, Vol. 16, No. 2, pp. 281-301 (2010).

170. Zhang, H., Xie, X., and Zhao, J. L., "Parametric vibration of carbon fiber reinforced plastic cables with damping effects in long-span cable-stayed bridges," Journal of Vibration and Control, Vol. 17, No. 14, pp. 2117 2130 (2011).

171. Zhang, L., Dupuis, R., and Dupuis, X., "Measurement and identification of dynamic properties of flexible polyurethane foam," Journal of $\mathrm{Vi}$ bration and Control, Vol. 17, No. 4, pp. 517-526 (2011).

172. Zhang, X., Mills. J. K., and Cleghorn, W. L., "Experimental implementation on vibration mode control of a moving 3-PRR flexible parallel manipulator with multiple PZT transducers," Journal of Vibration and Control, Vol. 16, No. 13, pp. 2035-2054 (2010).

173. Zhang, Y., Huang, X., and Zhao, Q., "Sensitivity analysis for vibration transfer path systems with non-viscous damping," Journal of Vibration and Control, Vol. 17, No. 7, pp. 1042-1048 (2011).

174. Zhang, Y., Sharf, I., and Sharf, X., "Force reconstruction for low velocity impacts using force and acceleration measurements," Journal of Vibration and Control, Vol. 17, No. 3, pp. 407-420 (2011).

175. Zhao, H., "Repetitive learning control of a flexible whisker in tip contact with an unknown surface," Journal of Vibration and Control, Vol. 17, No. 2, pp. 197-203 (2011).

176. Zhao, M., "Stochastic optimal semi-active control of stay cables by using magneto-rheological damper," Journal of Vibration and Control, Vol. 17, No. 13, pp. 1921-1929 (2011).

177. Zhao, Y., "Vibration suppression of a quadrilateral plate using hybrid piezoelectric circuits," Journal of Vibration and Control, Vol. 16, No. 5, pp. 701-720 (2010).

178. Zhao, Y., "Vibration control of seat suspension using $\mathrm{H}^{\infty}$ reliable control," Journal of Vibration and Control, Vol. 16, No. 12, pp. 1859-1879 (2010).

179. Zheng, L. A., Ho, W. H., Chou, J. H., and Chen, S. H., "Robust-optimal active vibration controllers design of flexible mechanical systems via orthogonal function approach and genetic algorithm," Journal of Vibration and Control, Vol. 17, No. 2, pp. 223-234 (2011).

180. Zhu, H. B., Kai, H. M., and Eguchi, K., "Application of BPNN in classification of time intervals for intelligent intrusion decision response system," International Journal of Innovative Computing, Information and Control, Vol. 4, No. 10, pp. 2483-2491 (2008).

181. Zhu, J., Ye, G. R., Xiang, Y. Q., and Chen, W. Q., "Dynamic behavior of cable-stayed beam with localized damage," Journal of Vibration and Control, Vol. 17, No. 7, pp. 1080-1089 (2011). 